\title{
DEVELOPMENT OF A MEASURING AND CONTROL UNIT FOR AN INTELLIGENT ADJUSTMENT OF PROCESS PARAMETERS IN SAWING
}

\author{
F. Schreiner ${ }^{1 *}$, B. Thorenz ${ }^{1}$, J. Schmidt ${ }^{1}$, M. Friedrich ${ }^{1}$, F. Doepper ${ }^{1,2}$ \\ ${ }^{1}$ University of Bayreuth, Chair Manufacturing and Remanufacturing Technology, Bayreuth, Germany \\ ${ }^{2}$ Fraunhofer IPA Project Group Process Innovation, Bayreuth, Germany \\ ${ }^{*}$ Corresponding author; florian.schreiner@uni-bayreuth.de
}

\begin{abstract}
Sawing frozen wood differs significantly from sawing unfrozen wood. Temperatures below zero degrees result in an increasing hardness of wood, rising cutting forces and a progression of tool wear. Currently, the adaption of process parameters due to different wood temperatures is based on operator experience, leading to overloaded saw blades, hence causing considerable economic damage by increasing production downtime. This paper presents the development of a measuring and control unit featuring an integrated database of processing values enabling operators to use most suitable process parameters, thus extending the service life of circular saw blades and increasing the performance of sawmills.
\end{abstract}

\section{Keywords:}

Intelligent manufacturing; Circular sawing; Cutting conditions and their optimization; Machining of difficultto-cut materials

\section{INTRODUCTION}

In times of dwindling resources and competition between sawmills, cost- and energy-efficient sawing processes are increasingly coming into focus for operators [Greigeritsch 2009]. In this context, the processing of frozen wood has always represented a special challenge for sawmills [Orlowski 2009]. In particular, wood temperatures below the freezing point lead to increasing cutting forces during circular sawing [Schmidt 2018]. A connection with the hardness of ice is obvious at this point. According to Mohs' hardness scale, ice only has a low hardness of 1.5 at a few degrees below zero and can be scored with a fingernail. However, the Mohs' hardness of ice increases at lower temperatures. At $-30{ }^{\circ} \mathrm{C}$, its hardness of 3.5 exceeds that of limestone (hardness 3 ) until it finally reaches the hardness of quenched and tempered steel (Mohs' hardness about 6) at $-80^{\circ} \mathrm{C}$. [Juhnke 2006] This increasing hardness has a direct influence on the course of tool wear and thus on the service life of circular saw blades. Sawmills in areas with cold average annual temperatures, such as Alaska or northern parts of Russia and Canada, are regularly confronted with average temperatures of down to $-35^{\circ} \mathrm{C}$ in the winter months [Sajadi 2020].

To meet this challenge, process parameters such as feed rate are controlled according to the temperature of the wood, which is assumed to be constant throughout the log due to the duration of the cooling process. Currently, this control is based solely on operator experience, which often forces the circular saw process to stop due to overloaded circular saw blades, thus increasing production downtime and causing significant economic damage.

\begin{tabular}{|ll|}
\hline Nomenclature & \\
$a_{e}$ & cutting depth \\
$b$ & chip width \\
$\tilde{c}$ & constant \\
$d$ & diameter \\
$\varepsilon$ & emissivity \\
$F_{c}$ & cutting force \\
$F_{c, m e a}$ & cutting force, measured \\
$F_{c, r e f}$ & cutting force, reference \\
$f_{z}$ & feed rate per tooth \\
$h_{m}$ & average wood chip thickness \\
$k_{c}$ & specific cutting force \\
$M_{t}$ & torsional moment \\
$n$ & rotational speed \\
$P_{c}$ & process power \\
SD & standard deviation \\
$T_{l}$ & log (wood) temperature \\
$U$ & voltage \\
$v_{c o}$ & coefficient of variation \\
$v_{f}$ & feed rate \\
$v_{f, r e c}$ & feed rate, recommended \\
$v_{f, r e f}$ & feed rate, reference \\
$z$ & number of teeth \\
$z_{e}$ & teeth in engagement \\
\hline
\end{tabular}




\section{STATE OF THE ART}

Circular sawing of frozen wood has always been a challenging task for sawmills. In order to address and overcome these challenges special attention must be paid to occurring physical and mechanical changes when cutting frozen wood. It is known that mechanical properties of wood are influenced by several factors such as wood temperature and moisture content [Gerhards 1982].

It is observed that the most pronounced changes in cutting forces in circular sawing of wood occurs when wood temperatures drop below freezing point in combination with a moisture content at or above the fibre saturation point of wood [Niemz 2017]. This circumstance can be explained by the occurrence of the two following phenomena. Hernandez et al. [Hernández 2014] found that the first phenomenon revolves around the fact that wood with a sufficient amount of water meets or exceeds the fibre saturation point, hence containing free water in the cell luminas, which will freeze at temperatures below $0{ }^{\circ} \mathrm{C}$. Once the water has turned into ice, it is exerting a compressive force on the cell walls of the wood, thereby reinforcing them and making the wood harder to cut. Kubler et al. [Kubler 1973] found that the second phenomenon exists due to the outwards migration of water in the wood cell walls, which subsequently condenses as ice crystals on the cell walls. The ice crystals contribute to the reinforcement of the cell walls. Furthermore Shmulsky [Shmulsky 2006] states that the migration of water drains the cell walls, which subsequently alters the mechanical characteristics resulting in an increase of cutting force. Greenwood, which is wood that has recently been felled, is the main type of wood processed in sawmills and generally contains enough water to reach its fibre saturation point. This makes greenwood prone to a significant increase in cutting force when temperatures decrease below freezing point.

Vazquez-Cooz and Meyer [Vazquez-Cooz 2006] conducted several cutting tests in various humidity levels and temperature ranges using wood of red maple and sugar maple. The results show the lowest cutting forces for green unfrozen wood and the highest cutting forces for dry unfrozen wood. The cutting force of dry wood did not differ significantly from the cutting force of frozen wood for the sugar maple, however a significant difference in cutting forces of frozen and dry wood for the red maple could be obeserved. M. Ispas and M. Câmpean [Ispas 2014] show contrary findings to the aforementioned behaviour in their research on sawing power and specific resistance when sawing frozen and unfrozen spruce wood with a circular buzz saw. An adjusted saw blade and a low cutting height were used, which avoided the common phenomenon of large quantities of sawdust getting stuck on the lateral kerf walls, thus decreasing the frictional resistance. The authors found that the cutting force of frozen wood generally is not increased due to the interaction between the circular saw blade and the wood, however due to low sawdust evacuation in conventional circular sawing processes.

Several authors aim to compensate the effect of wood temperatures below freezing point by the use specific correctional factors when sawing frozen wood [Orlowski 2009]. Lunstrum e.g. recommends to reduce the cutting speed of the circular saw to about $30 \%$ of its normal value when sawing frozen wood to keep the tool wear at an acceptable level [Lunstrum 1985].

\footnotetext{
1 Spruces represent the most common tree species in Germany
[BMEL 2018] and are also mainly processed in the sawmill where

1 Spruces represent the most common tree species in Germany
[BMEL 2018] and are also mainly processed in the sawmill where the $\mathrm{MCU}$ is to be tested in practical use, see section 4.3.
}

The given literature shows contradictory recommendations (correction factors) for the compensation of negative effects on the cutting force when sawing frozen wood. As stated by Vazquez-Cooz and Meyer there is a great number of factors biasing the cutting force which need to be taken into account when conducting studies on the effects of wood temperatures [Vazquez-Cooz 2006]. Therefore, these recommendations can only be understood as a rough guideline when dealing with the effects of temperatures below freezing point. Hence, the values for the cutting forces required in this paper are obtained using an experimental setup which follows the respective industrial application of a circular wood sawing process in a sawmill as accurately as possible in terms of wood temperature, moisture content and type of wood. This approach ensures obtaining reliable values for the cutting forces of different temperatures.

\section{EXPERIMENTAL SETUP AND CREATION OF A DATABASE FOR SAWING FROZEN WOOD}

As described in chapter 2, increased process power is required when sawing frozen wood. To regulate the applied process power by the planned measuring and control unit (MCU), the relationships between cutting force $F_{c}$, process power $P_{c}$ and the temperature of the wood to be sawn must first be determined. For this purpose ${ }^{1}$, experimental tests are carried out in a laboratory environment, in which spruce wood specimens are sawn both at room temperature at $20^{\circ} \mathrm{C}$ and at wood temperatures between 0 and $-35^{\circ} \mathrm{C}$ in $5^{\circ} \mathrm{C}$ decrements. The minimum temperature considered represents the minimum average temperature which sawmills located in cold regions are confronted with in winter months [Sajadi 2020]. The wood specimens are cooled down gradually to the next lower temperature level over a duration of at least 24 hours. Additional measurements have shown that the wood specimens are completely cooled down to the new temperature level during that amount of time. The spruce wood specimens have a moisture content of $29 \%$, which is determined by the oven dry method according to the DIN EN 13183 [DIN 2002]. The dimension of the specimens amounts to $90 * 90 * 180 \mathrm{~mm}$. The saw operations were performed on a DMU 50 eVolution five axis machining center using an insertable two teeth circular sawblade, developed for experimental setups. The cutting force was measured with a sensory tool holder from pro-micron $\mathrm{GmbH}$ (see Fig. 1).

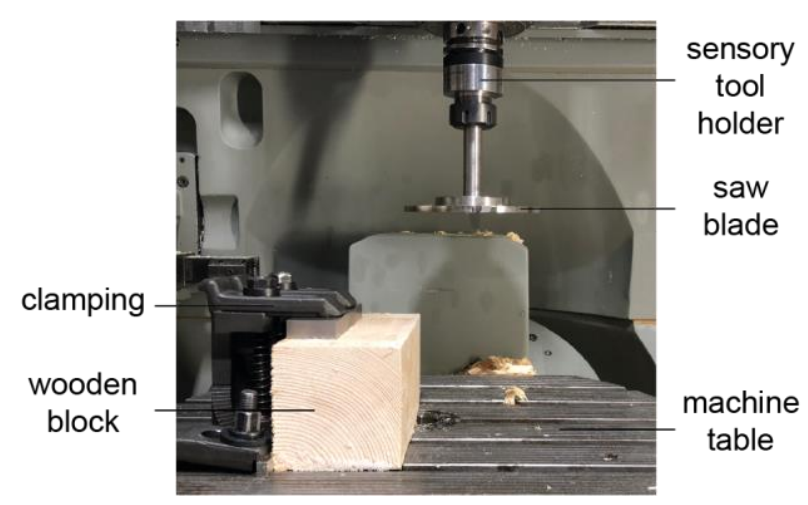

Fig. 1: Experimental setup for determining cutting forces when sawing frozen wood. 
The wood specimens were clamped so that cuts could be made along the wood fibre direction to ensure a cut analogous to the sawing process of a log in a sawmill. Kivimaa defines the used direction as cutting direction $B$ [Kivimaa 1950] (see Fig. 2).
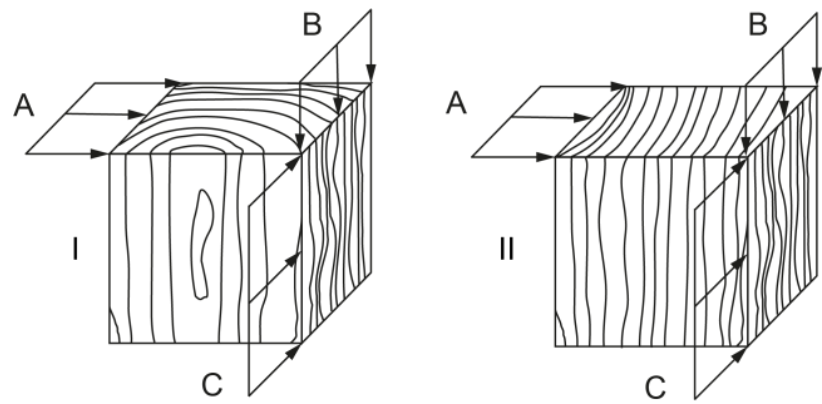

Fig. 2: Schematic representation of the three fibre cutting directions A, B, C in two cutting instances I and II [Kivimaa 1950].

A feed rate $v_{f}$ of $1,066.9 \mathrm{~mm} / \mathrm{min}$ and a rotational speed $n$ of $3301 / \mathrm{min}$ were selected as process parameters, as these are recommended for the two teeth saw blade. The torsional moment $M_{T}$ occurring in the sawing process can be measured by the sensory tool holder. Thus conclusions can be drawn about the occurring cutting force $F_{C}$ as well as the process power $P_{C}$ through the correlations shown in the following equations (1) and (2) [Apprich 2015; Pauksch 2008; Ettelt 2004]:

$F_{C}=\frac{M_{T}}{\frac{d}{2} \cdot z_{e}}$

$P_{c}=F_{c} \cdot v_{c}$

Due to the anisotropic and inhomogeneous material properties of wood and therefore strongly varying cutting forces $F_{c}$, nine cuts per temperature level were made, from which an average value for the corresponding cutting force was determined. The following Fig. 3 shows the average cutting forces and standard deviations (SD) measured at different temperature levels.

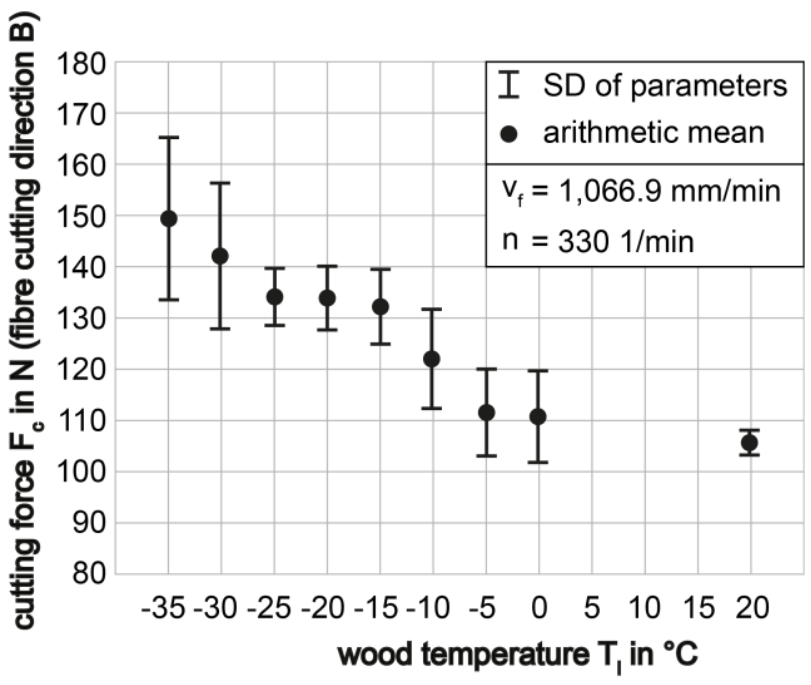

Fig. 3: Average cutting forces $\boldsymbol{F}_{\boldsymbol{c}}$ at varying temperatures.

The measurement results indicate that the resulting cutting force $F_{c}$ increases significantly when sawing frozen wood and a clear upward trend becomes apparent at colder wood temperatures. While an average cutting force $F_{c}$ of $106.3 \mathrm{~N}$ was detected for wood at room temperature, the cutting force increased to $111.4 \mathrm{~N}$ at wood temperatures around the freezing point, which marks a $4.5 \%$ rise. At a wood temperature of $-20{ }^{\circ} \mathrm{C}$, the average cutting force $F_{c}$ was indicated at $134.3 \mathrm{~N}$, which is a $20.8 \%$ rise in average cutting force $F_{c}$ when compared to room temperature. In the temperature range considered the highest average cutting force $F_{c}$ was measured at $-35^{\circ} \mathrm{C}$, indicating $148.6 \mathrm{~N}$ and thus a $28.5 \%$ rise when compared to the average cutting force $F_{c}$ at room temperature.

Furthermore, it is noticeable that the scatter of the measured values increases strongly with decreasing wood temperature. While the coefficient of variation $v_{c o}$ is 0.02 when sawing wood at room temperature, $v_{c o}$ is at least 0.04 for frozen wood and 0.10 for wood temperatures as low as $-35^{\circ} \mathrm{C}$. Unlike the average cutting force $F_{c}$, no clear trend could be observed for scatter with decreasing temperatures in this study. On the one hand, this can be explained by the anisotropic and inhomogeneous properties of spruce wood. On the other hand, it must be assumed that the water which makes up the moisture content is not evenly distributed within a wood specimen. While this is no problem for unfrozen wood, at colder temperatures wood has frozen areas which are harder and therefore more difficult to saw due to a higher moisture content.

The measured cutting forces $F_{c, \text { mea }}$ are then used to interpolate a characteristic curve, on which basis process parameter recommendations for the processing of frozen wood can be derived. This procedure is described in the following chapter 4 .

\section{MEASURING AND CONTROL UNIT}

\subsection{Setup of the measuring and control unit}

The MCU is developed and built in accordance to VDI guideline 2221-2 [VDI 2221]. Particular attention must be paid towards a flexible design of the MCU in order to ensure its high adaptability to different operating conditions. Fig. 4 shows the general setup of the MCU.

The frame was designed so that it can be easily adapted to the particular conditions in the sawmill.

The computing unit is built of a Raspberry Pi 4 Model B 4GB SDRAM and a PiXtend V2-S forming the core of the MCU. The computing unit is programmed to record the sensor data and control the solenoid valve. The components pyrometer, reflex sensor and solenoid valve are directly connected to the PiXtend and are operated using the Raspberry Pi 4.

A pyrometer is used for measuring the temperature on the surface of the wood. The pyrometer is a Modell CT LT15 of the Optris $\mathrm{GmbH}$. Its spectral sensitivity lies within the range of $8-14 \mu \mathrm{m}$ and therefore is suitable for non metallic surfaces. Temperatures ranging from -50 to $600{ }^{\circ} \mathrm{C}$ can be measured with a resolution of $0.01 \mathrm{~K}$ and a system accuracy of $\pm 1{ }^{\circ} \mathrm{C}$. The setting time for a measuring point (95\% signal) amounts to $150 \mathrm{~ms}$ which therefore marks the time for taking a reliable temperature measurement. The pyrometer consists a measuring head, which needs to be aligned with the object and an electrical box, containing the evaluation electronics allowing several settings for signal processing to be altered. The emissivity and transmittance can be set according to the use case. These values are then taken into account to determine the output signal. For wooden surfaces, the emissivity ranges between 0.89-0.92 [Rice 2004]. The pyrometer records the intensity of the infrared radiation within a measuring spot. The diameter of the measuring spot is dependent on the distance between measuring spot and measuring object. In this study, the setup of the MCU ensures an appropriate distance between 


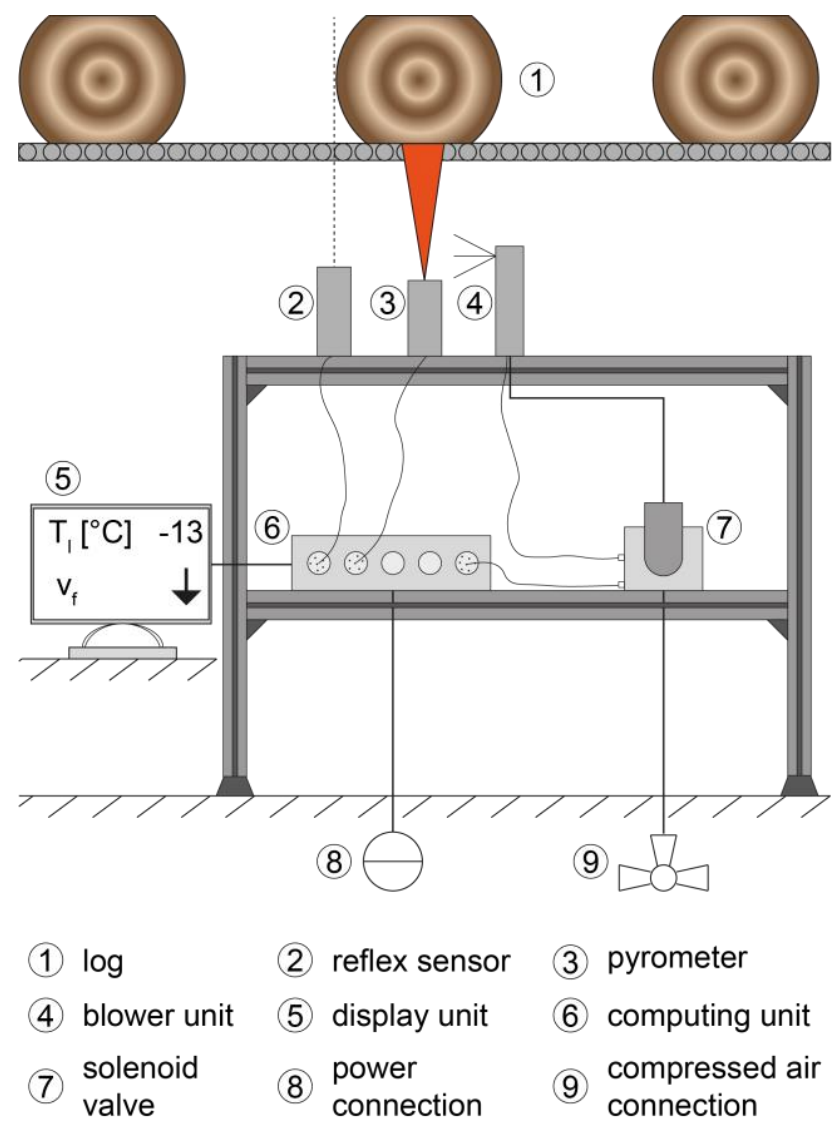

Fig. 4: General setup of the MCU.

pyrometer and wood, creating a measuring spot within the dimensions of the wood.

For the detection of passing logs, which are being transported on a roller conveyor, a reflex sensor is used. The reflex sensors is a Modell TC 66 PA3 of the wenglor sensoric $\mathrm{GmbH}$. The MCU is placed underneath the roller conveyor, hence positioning the reflex sensor in an optimal distance and angle to capture the passing logs. The Wenglor TC 66 PA3 reflex sensor has a response time of $0.5 \mathrm{~ms}$ and a switching frequency of $1,000 \mathrm{~Hz}$, which by far exceeds the requirements of the measurement setup.

The blower unit is mounted on top of the frame of the MCU. Its purpose is to free the reflex sensor and the pyrometer from dust and sawdust contamination by using compressed air. The sawdust is constantly being generated by the circular sawing of wood and therefore needs to be removed regularly. The blower unit is connected to the solenoid valve, which in turn is connected to a compressed air line. A 2/2 way solenoid valve from RIEGLER is used with a $24 \mathrm{~V}$ power supply.

\subsection{System logic of the measuring and control unit}

The system logic behind the MCU ensures a proper functioning of the cutting force adaption process for frozen wood. Fig. 5 shows the program sequence for recording and evaluating the sensor data for a log. Fig. 5 (left column) shows the event loop of the program, which serves as the main window and allows for user input, while Fig. 5 (right column) shows the three program threads WorkerPyro, WorkerMagnet and WorkerOptical. Upon starting the program, all settings are loaded from the configuration file and the user interface (UI) elements are initialized. Subsequent to the initializing process the threads WorkerPyro and WorkerOptical are started. Starting the thread WorkerMagnet for operating the solenoid valve can either be set to run upon the start of the program or be started manually.

The thread WorkerOptical queries the measuring signals of the reflex sensor at a fixed time interval. As soon as a change in the measuring signal is detected, a signal, connected to the 'on_optical_signal()' slot in the event loop, is emitted. If a log was detected, the old content of the array in which the measured values are saved is deleted in order to allow the storage of the current log's measured values. This process starts over once a new log is detected.

The thread WorkerPyro functions similarly to the thread WorkerOptical. The measuring signals of the pyrometer are queried, then the data is sent to the 'update ()' slot in the EventLoop and carried out. The measured values are stored in an array until an initially specified maximum number of measured values to be recorded has been reached. The specified maximum number of measured values is editable by user input in the GUI and ought to be altered based on the diameter of the processed log, in order to maximize the yield of measured values. The function 'update ()', which is called each time a temperature value is recorded, contains the logic for storage and evaluation of the measured values. The course of the subroutines 'average data and evaluate it' and 'add data to series of measurement' will be discussed in detail in section 4.3.

The thread WorkerMagnet is used for operating the solenoid valve. The duration of the relay closed and the timer until an open relay is closed can be set as needed. The thread WorkerMagnet closes the relay of the solenoid valve causing air to blow. The subroutine 'wait(pressure duration)' keeps the relay closed for a preset amount of time. Once the relay opens, the airflow stops and the timer is activated. The subroutine 'wait(timer interval)' controls the time the relay is being kept open.

\subsection{Evaluation of the measured values}

Course of the subroutine 'average data and evaluate it' and 'add data to series of measurement'

The course of the subroutine 'average data and evaluate it' is shown in Fig. 6 (left column) and can be explained as follows. Once the previously specified maximum number of measured values to be recorded is stored in an array within the 'update ()' slot, the course of the subroutine 'average data and evaluate it' of the EventLoop is initiated and carried out by averaging the measured values to a single temperature value for the log. Then, by using the characteristic curve of the cutting force temperature link the subroutine outputs the cutting force $F_{c, \text { mea }}$ (see chapter 3 ). Taking the cutting force $F_{c, m e a}$, the reference cutting force $F_{c, \text { ref }}$ at room temperature and the reference feed rate at room temperature $v_{f, r e f}$ into consideration, the recommended feed rate for the previously calculated temperature value $v_{f, r e c}$ can be obtained, see equations (3) to (9).

The course of the subroutine 'add data to series of measurement' is shown in Fig. 6 (right column) and can be explained as follows. Once the values for the log temperature $T_{l}$, the cutting force $F_{c, \text { mea }}$ and the recommended feed rate $v_{f, r e c}$ of a log are obtained, they get included in the current measurement series. The measurement series contains the averaged values of the log temperature $T_{l}$, cutting force $F_{c, \text { mea }}$ and the recommended feed rate $v_{f, r e c}$ of all previously captured logs within that measurement series.

Cutting force $F_{c}$ and feed rate $v_{f}$

For proper usage of the MCU for an intelligent adjustment 


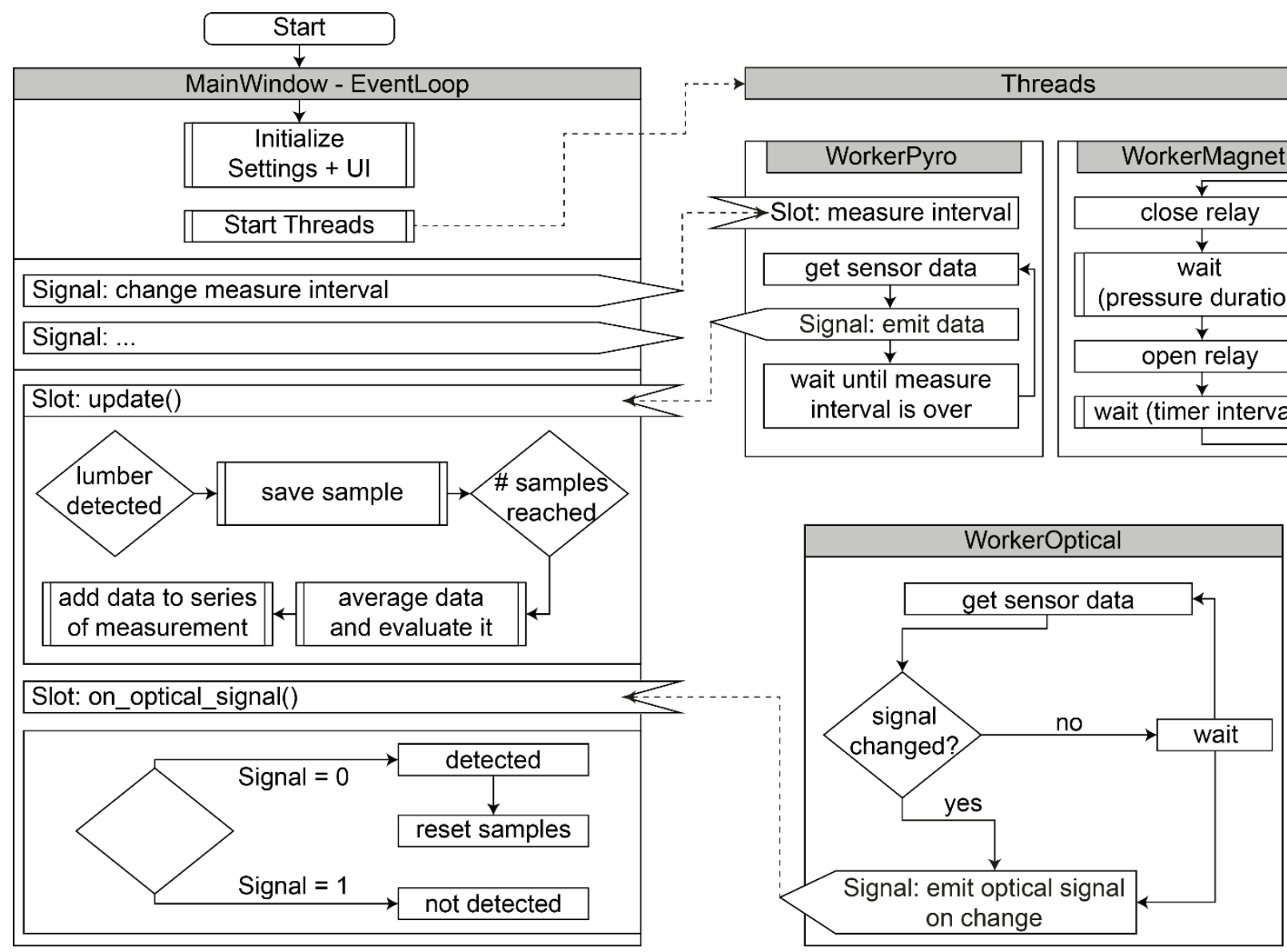

Fig. 5: System logic of the MCU.

of process parameters in the sawing process, it is necessary to establish a mathematical link between the cutting force $F_{c}$ and the feed rate $v_{f}$, which is described in this subsection. Wagenführ et al. [Wagenführ 2012] state the formula used for calculating the cutting force $F_{c}$ as follows:

$F_{c}=k_{c} \cdot h_{m} \cdot b=f(v, T)=g(T) \cdot h(v)$

Certain requirements must be met in order for equation (3) to be used: the average wood thickness $h_{m}$ must merely depend on the feed rate and hence does not depend on log temperature. The specific cutting force $k_{c}$ and the chip width $b$ must merely depend on log temperature and hence do not depend on the feed rate.

The cutting force $F_{c}$ depends on the feed rate $v_{f}$ and the log temperature $T_{l}$. The aim is to compensate the speeddependent part $h(v)$ with the temperature-dependent part $g(T)$ of the cutting force:

According to Ettelt and Gottlöber [Gottlöber 2014] the average wood chip thickness $h_{m}$ can be calculated as follows [Ettelt 2004]:

$h_{m}=h_{m}(v)=f_{z} \cdot \sqrt{\frac{a_{e}}{d}}=\frac{v_{f}}{n \cdot z} \cdot \sqrt{\frac{a_{e}}{d}}=v_{f} \cdot \tilde{c}$

Hence, there is a direct proportionality between the cutting force $F_{c}$ and the feed rate $v_{f}$. The remaining variables in $h_{m}$ do not depend on the log temperature $T_{l}$ and can be grouped to the constant $\tilde{c}$.

$F_{c}=k_{c} \cdot b \cdot v_{f} \cdot \tilde{c}=v_{f} \cdot \mathrm{g}(\mathrm{T})$

The cutting force $F_{c, \text { mea }}$ is derived from the measured log temperature values by using the characteristic curve of the cutting force temperature link (see chapter 3 ).
$F_{c, m e a}=v_{f, r e f} \cdot \mathrm{g}(\mathrm{T})$

The following formula applies at room temperature:

$F_{c, r e f}=v_{f, r e f} \cdot \mathrm{g}\left(\mathrm{T}_{\mathrm{RT}}\right)$

By using a targeted adaption of the feed rate $v_{f}$, the value of the cutting force $F_{c, \text { mea }}$ can be kept at the same level as the value of the cutting force $F_{c, r e f}$.

$F_{c, r e f}=v_{f, r e c} \cdot \mathrm{g}(\mathrm{T})$

The substitution of equation (6) into equation (8) yields the following mathematical link:

$\frac{F_{c, \text { mea }}}{F_{c, \text { ref }}}=\frac{v_{f, \text { ref }}}{v_{f, \text { rec }}} \Rightarrow v_{f, \text { rec }}=v_{f, \text { ref }} \cdot \frac{F_{c, \text { ref }}}{F_{c, \text { mea }}}$

The mathematical link demonstrates that the value of the recommended feed rate $v_{f, r e c}$ is derived from the reference feed rate at room temperature $v_{f, r e f}$, the reference cutting force $F_{c, r e f}$ and the cutting force $F_{c, \text { mea }}$.

\subsection{Practical application of the measuring and control unit}

The practical application of the MCU was carried out in a sawmill located in the north eastern part of Bavaria in April 2021. Spruce wood (picea abies) is predominantly processed in this sawmill and also was used for the practical application of the MCU. The sawmill processes 1,000 running meters of wood every day.

The MCU is integrated into the sawing line and set up in front of the entrance to the chipper canter line, see Fig. 7. Logs have to pass the chipper canter line several times. The first time a log passes through the chipper canter line, two planks are removed from two opposing sides of the log. This cut removes about $3 \mathrm{~cm}$ of the log on each side, ex- 


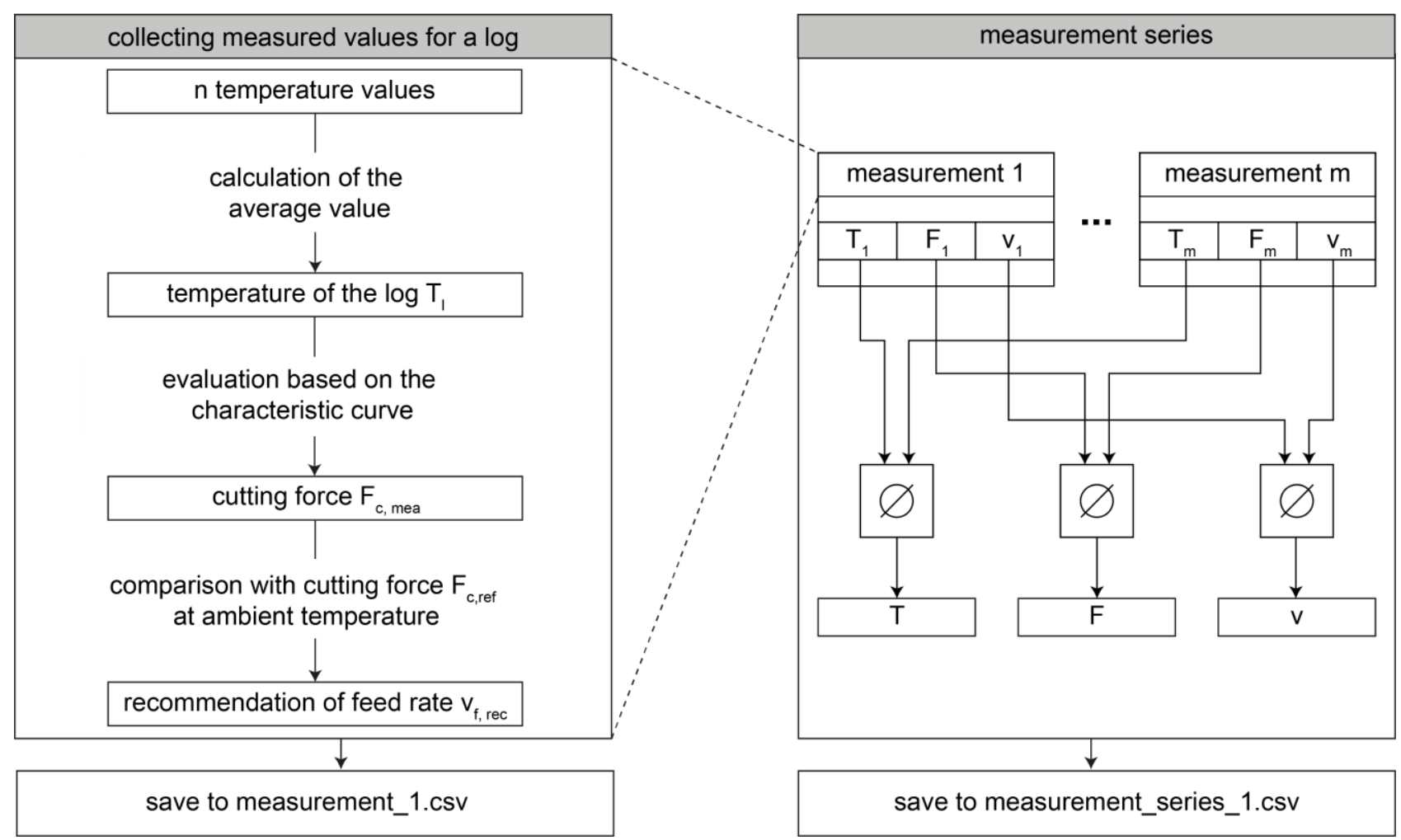

Fig. 6: Course of the subroutine 'average data and evaluate it'(left) and the subroutine 'add data to series of measurement'(right).

posing the log's sapwood. Once this is completed the log is moved back to the front of the chipper canter line in order to continue the sawing process. Close before the log enters the chipper canter line for the second time, the MCU takes the temperature of the log. This setup ensures optimal results, as it is possible to get data from the sap wood deeper inside the log instead of taking the temperature measurements of the bark. The MCU was active for 121 minutes until the practical application could be completed successfully. This amounted to 126 running meters of sawn wood while the MCU was in use. During this time, data was collected and recommendations for feed rates were shown. The operator used the implemented GUI to run the MCU.

It was necessary to create a GUI (Fig. 7 left) in order to enter data interactively, to observe measurements and their results and to customize various settings.

The operator can chose between different tabs when using the GUI of the MCU. The tab 'Main Window' allows to specify values for log diameter and number of circular saw blades currently in use. After the measuring process has started, the operator is able to receive recommendations for adapting the feed rate in real time. As shown in Fig. 4 the arrow shown on the GUI indicates the recommended action. An upwards pointing arrow indicates an increase in feeding rate whereas a downwards pointing arrow indicates to decrease the feed rate. The operator can terminate a measurement series and start a new one whenever deemed necessary. Up to the point of termination, the measurement series contains the values of all single measurements which were assigned to it.

The tab 'Solenoid Valve' enables the operator to set the solenoid valve according to the demand of compressed air due to the presence of saw dust (see Subsection 4.2).

In the tab 'Plots' the measurements of the pyrometer and the reflex sensor can be observed in real time. The tab 'Data Logging' is used to manually start, pause and terminate the logging of measurement data.
Unfortunately the climatic conditions did not allow proper operation of the MCU within ideal conditions. The outside temperature was listed as $8^{\circ} \mathrm{C}$, hence there were no frozen logs available at that time. However the practical application could be used as a proof of concept, as the operator of the saw line was able to get recommendations for the most suitable feeding rates for the given temperatures. There were no incidents reported in the function of the MCU. The air blower was connected to a high pressure line of the sawmill, delivering a constant pressure of 8.0 bars keeping the pyrometer and the reflex sensor clean at all times. Hence, the validation of the MCU was carried out using an experimental setup imitating the industrial conditions in a sawmill during winter times. A test stand was used which allowed a continuous simulation of frozen wood passing overhead the MCU and therefore imitating the conveyor belt of the saw line. As specimens, frozen wood planks were used with a temperature ranging between -20 to $5^{\circ} \mathrm{C}$. The frozen specimens could be detected and temperature values were collected making the validation process successful.

During the winter months, the sawmill has to deal with frozen logs, which results in increased power consumption of the saw station drive motors and increased wear of the circular saw blades. The feed rates of the frozen logs represent the only reasonable possibility for the machine operator to adapt the sawing process to the climatic conditions. The operator acts only from experience and tries to keep the energy consumption and thus the wear of the saw blades at one level. Although this procedure reduces the process throughput due to reduced feed rates, it prevents saw blade failure and thus a time-consuming tool change operation. Fig. 8 schematically shows the potential that arises when using the MCU to adjust the feed rate of the sawing process. It is clear that the power consumption increases sharply with decreasing temperatures without adjustment of the feed rate. This results from the increased cutting force $F_{c}$, see chapter 3 , and leads to a constant pro- 


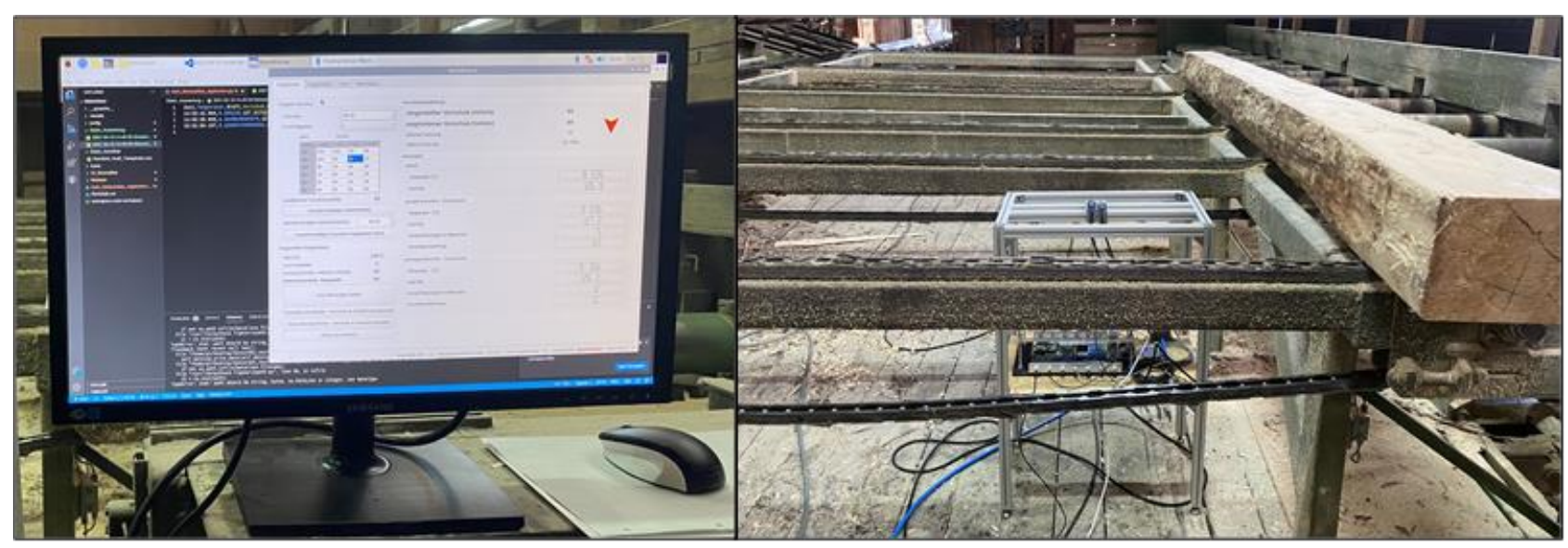

Fig. 7: Practical use in the sawmill: Main window tab of the GUI (left) and MCU in practical use (right).

cess throughput, but also to increased tool wear and thus to more frequent time-consuming tool changes. If the feed is adjusted based on the operator's experience, there is a risk that the operator will overestimate or underestimate the influence of the frozen wood. This risk is particularly increased for inexperienced machine operators. If the influence of frozen wood is overestimated and the feed rate therefore is decreased too much, this leads to lower power consumption and wear, but the process throughput is also disproportionately reduced. If the influence of frozen wood is underestimated, increased power consumption and tool wear will occur despite the adjustment of the feed rate.

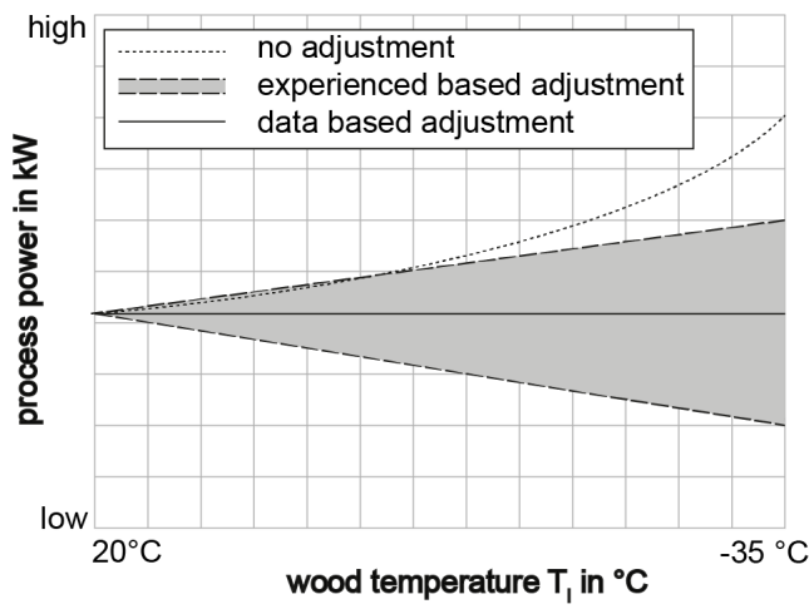

Fig. 8: Influence of the wood temperature on the power consumption of the sawing process with different feed rate adjustment strategies.

Based on the daily average temperatures that occur in the area of the considered sawmill, the MCU would display the average feed rate adjustment recommendations as shown in Tab. 1 during the winter months. In particular, the timeof-day-dependent development of the wood temperature should be recorded by the MCU and enable the machine operator to adjust the feed rate in real time and thus keep the level of energy consumption and wear behaviour of the saw blades constant and therefore predictable.

A market study among manufacturers and users of circular saw blades as part of the research project in which the MCU was created, showed that the average time for a tool change in a sawmill is 66 minutes. In the considered sawmill, a tool change is carried out as scheduled at every shift change, which means that a tool failure during a shift causes high costs. Depending on the design and cost of the sawing process, potential users of the MCU must compare the cost of reduced process throughput to the cost saved on energy and unscheduled tool changes.

\section{CONCLUSION AND OUTLOOK}

The development of a MCU for an intelligent adjustment of process parameters in the circular sawing process of wood was successfully completed. The MCU contains an integrated database of occurring cutting forces at different temperature levels ranging from -35 to $20{ }^{\circ} \mathrm{C}$ when sawing greenwood logs.

The database was created using an experimental setup for the determination of cutting forces at different temperature levels. The experimental setup consisted of a two teeth circular saw blade which cut into in dimensions, moisture content and cutting directions predefined wood specimens. It was observed that the resulting cutting force $F_{c}$ significantly increases when sawing frozen wood. Furthermore a clear upward trend in cutting force $F_{c}$ could be detected for declining temperatures below the freezing point. The maximum cutting force was detected at the lowest examined temperature with a $28.5 \%$ rise in cutting force when compared to the cutting force at room temperature level for the used specimen. An apparent increase in scatter could be noted when the wood temperature was reduced below the freezing point. However it was not possible to clearly identify a trend in the scatter, once the temperature was reduced further below the freezing point of the specimens. After the database was created the setup of the MCU was carried out which included the implementation of a system logic suitable for

Tab. 1 : Expected average feed rate adjustment recommendation of the measurement and control unit in the sawmill under consideration

\begin{tabular}{|c|c|c|c|c|c|}
\hline Month & November & December & January & February & March \\
\hline Avg. Temperature $\left[{ }^{\circ} \mathrm{C}\right]$ & -2.9 & -6.0 & -7.6 & -7.2 & -5 \\
\hline $\begin{array}{l}\text { Recommended adjustment } \\
\text { of feed rate [\%] }\end{array}$ & $-4,7 \%$ & $-6,7 \%$ & $-10,0 \%$ & $-9,2 \%$ & $-4,7 \%$ \\
\hline
\end{tabular}


the detection of logs, logging of relevant data and dynamically recommending an optimal feed rate for the wood sawing process for various temperatures. The practical application of the MCU in a commercial sawmil showed a proper functioning of the unit. Additional tests with wood specimen, which were cooled down to a predefined temperature level were conducted in order to demonstrate the proper functioning of the MCU within a wide range of temperatures.

In conclusion the MCU functioned properly and without the occurrence of problems when used during the practical application and was able to recommend feeding rates which were optimal for lowering cutting forces and prolonging the lifespan of the circular saw blade.

As part of further research work, the results of the projections from section 4.4 will be validated through an industrial application of the MCU in winter months with outside temperatures well below freezing point.

\section{ACKNOWLEDGMENTS}

All topics presented in this paper are outcomes of the research project "High performance circular saw blades for processing frozen wood" (Hochleistungskreissägeblätter zur Bearbeitung von gefrorenem $\mathrm{Holz}$ ). The authors would like to express their gratitude to the Central Innovation Program for medium-sized businesses (Zentrale Innovationsprogramm Mittelstand) for funding to make this research work possible.

\section{REFERENCES}

[Apprich 2015] Apprich, T. Tabellenbuch für Zerspantechnik. Haan-Gruiten, Verlag Europa-Lehrmittel, 2015.

[BMEL 2017] Bundesministerium für Ernährung und Landwirtschaft. Der Wald in Deutschland - Ausgewählte Ergebnisse der dritten Bundeswaldinventur. 3rd Edition, Berlin, 2018.

[DIN 2002] DIN DEUTSCHES INSTITUT FÜR NORMUNG 8.V., 2020. EN, D. 13183-1. "Feuchtegehalt eines Stückes Schnittholz. Teil I: Bestimmung durch Darrverfahren". Deutsche Fassung EN ISO 13183-I:2002. Berlin, Beuth Verlag $\mathrm{GmbH}, 7 / 2002$.

[Ettelt 2004] Ettelt, B. and Gittel, H.-J. Sägen, Fräsen, Hobeln, Bohren. 3rd Edition, Leinfelden-Echterdingen, DRW-Verlag Weinbrenner, 2004.

[Gerhards 1982] Gerhards, C.C. Effect of the moisture content and temperature on the mechanical properties of Wood. An analysis of immediate effects. Wood and Fiber, 1982, Vol. 14, No. 1, pp 436.

[Gottlöber 2014] Gottlöber, C. Zerspanung von Holz und Holzwerkstoffen. Grundlagen-Systematik-ModellierungProzessgestaltung. München: Fachbuchverlag Leipzig im Carl Hanser Verlag, 2014. ISBN 978-3-446-44003-6.

[Greigeritsch 2009] Greigeritsch, T. Neue Methoden zur Planung und Optimierung der Schnittholzproduktion von Nadelholzsägewerken. Wiesbaden: Gabler Verlag, 2009.

[Hernández 2014] Hernández et al. Effects of temperature and moisture content on selected wood mechanical properties involved in the chipping process. Wood Science and Technology, October 2014, Vol. 48, pp 12811301.

[Juhnke 2006] Juhnke, M. and Weichert, R. Erzeugung von Nanopartikeln durch Feinstzerkleinerung bei hohen Reinheitsanforderungen. In: mvt.tu-clausthal.de. Institut für
Mechanische Verfahrenstechnik, Technische Universität Clausthal, 2006, p. 13, accessed on 2021-05-24.

[Kivimaa 1950] Kivimaa, E. Cutting force in wood-working. Helsinki: Finland Institute of Technologie, 1950.

[Kubler 1973] Kubler et al. Thermal Expansion of moist wood, Madision, W.I. University of Wisconsin, Department of Forestry, 1973.

[Ispas 2014] Ispas, M. and Câmpean, M. Experimental research on sawing frozen wood. Bulletin of the Transylvania University of Brasov. 2014, Vol. 7, No.1, pp 5158.

[Lunstrum 1985] Lunstrum, S.J. Balanced Saw Performance. Technical Report No.12. Madison, WI: U.S. Department of Agriculture, Forest Service, Forest Products Utilization, 1985.

[Niemz 2017] Niemz, P. and Sonderegger, W. Holzphysik. Physik des Holzes und der Holzwerkstoffe. München, Fachbuchverlag Leipzig im Carl Hanser Verlag, 2017. ISBN 978-3-446-44546-8.

[Orlowski 2009] Orlowski et al. Sawing frozen wood with narrow kerf saws: Energy and Quality Effects. Forest Products Journal, 2009, Vol. 59, No. 3, pp 7983.

[Pauksch 2008] Pauksch, E. et al. Zerspantechnik: Prozesse, Werkzeuge, Technologien. Wiesbaden, Vieweg + Teubner Verlag, 2008.

[Rice 2004] Rice, R.W. Emittance factors for infrared thermometers used for wood products. Wood and Fiber Science, 2004, Vol.36, No. pp 520526.

[Sajadi 2020] Sajadi, M. et al. Temperature, Humidity, and Latitude Analysis to Estimate Potential Spread and Seasonality of Coronavirus Disease 2019 (COVID-19). Baltimore: University of Maryland, 2020.

[Schmidt 2018] Schmidt et al. Sustainability of cutting frozen wood - an analysis of buzz saw blades cutting performance depending on wood temperature. Procedia Manufacturing 25, 2018, pp 263270.

[Shmulsky 2006] Shmulsky, R. and Shvets, V. The effect of subzero temperatures on FSP of cottonwood, Forest Products Journal, February 2006, Vol. 56, No. 2, pp 7477.

[Vazquez-Cooz 2006] Vazquez-Cooz, I. and Meyer, R.W. Cutting forces for tension wood and normal wood of maple. Forest Products Journal, April 2006, Vol. 56, No 2, pp 2634.

[VDI 2221] VDI: VDI Richtlinie 2221-2: Entwicklung technischer Produkte und Systeme - Gestaltung individueller Produktentwicklungsprozesse. Beuth Verlag, Berlin, 2019.

[Wagenfuehr 2012] Wagenfuehr, A. and Scholz, F. Taschenbuch der Holztechnik. Muenchen: Fachbuchverlag Leipzig im Carl Hanser Verlag, 2012. ISBN 978-3-44643179-9. 